\title{
New Insight into Toxicity due to Oligomeric Amyloid- $\beta$ Peptide and Alpha-Synuclein Protein induced by Copper(II) ion
}

\author{
Keita Abe $^{1}$, Hiroshi Sakiyama ${ }^{2}$ and Yuzo Nishida ${ }^{3}$ \\ ${ }^{1}$ Wayo Konodai Girls’ Pasadera HS, Konodai 2-3-1, Ichikawa, 272-8533, Japan \\ ${ }^{2}$ Department of Chemistry, Yamagata University, Yamagata 990-8585, Japan \\ ${ }^{3}$ Medical Research Institute, Kanazawa Medical University, Uchinada, 920-0293, Japan \\ Correspondence: Yuzo Nishida, Medical Research Institute, Kanazawa Medical University, Uchinada, 920-0293, \\ Japan. E-mail: nsd-2210@kanazawa-med.ac.jp
}

Received: October 29, 2014 Accepted: December 19, $2014 \quad$ Online Published: December 29, 2014

doi:10.5539/ijc.v7n1p41 URL: http://dx.doi.org/10.5539/ijc.v7n1p41

\begin{abstract}
It is well known that Alzheimer's and Parkinson's diseases are closely related with the aggregated forms of amyloid- $\beta$ peptide and alpha-synuclein ( $\alpha$-syn) protein, respectively, and the recent work shows that neurotoxicity due to oligomeric $\alpha$-syn requires the presence of copper but not iron ion. In this article, we have proposed the new insight into the toxicity due to the oligomeric amyloid- $\beta$ peptide and $\alpha$-syn protein induced by the copper(II) ion, based on the Nishida Reaction which is specific for the binuclear copper(II) compounds where two copper(II) ions are in close vicinity, and that copper(II)-peroxide adduct exhibits strong electrophilicity towards several organic compounds similar to the singlet oxygen $\left({ }^{1} \Delta_{\mathrm{g}}\right)$.
\end{abstract}

Keywords: dementia, amyloid- $\beta$ peptide, $\alpha$-synuclein, oligomer, copper(II) ion

\section{Alzheimer's Disease and Amyloid- $\beta$ Protein}

Dementia is characterized by the loss of or decline in memory and other cognitive abilities. Alzheimer's disease (AD) is the most common type of dementia and accounts for an estimated $\sim 70 \%$ of cases. AD is an irreversible, progressive neurodegenerative disorders leading invariably to death usually within several years of diagnosis (Roberts, Ryan, Bush, Maters, \& Duce, 2012; Kenche \& Barnham, 2011; Gaeta \& Hider, 2005). The pathognomonic indicators of $\mathrm{AD}$ are the presence of senile plaques, neurofibrillary tangles, amyloid- $\beta$ peptide (A $\beta$ ) deposition and selective loss of neuron in the post-mortem brain. Deposition of amyloid plaques in AD is most obvious pathological feature; the major constituent of these deposits is the A $\beta$ peptide that is proteolytically cleaved from the membrane bound amyloid precursor protein (APP) (Roberts, Ryan, Bush, Maters, \& Duce, 2012; 2012; Kenche \& Barnham, 2011). Many hypotheses have been proposed for the mechanism by which A $\beta$ induces its neurotoxic effects, but at present there is a growing interest in soluble oligomers of $A \beta$, which have been thought to be most toxic (Kenche \& Barnham, 2011).

Synaptic dysfunction has been implicated as the primary cause of the memory deficits associated with $\mathrm{AD}$, and $\mathrm{Cu}$ and $\mathrm{Zn}$ have been reported to play key roles in regulating synaptic function (Roberts, Ryan, Bush, Maters, \& Duce, 2012). $\mathrm{Cu}$ has been shown to potentiate the toxicity of $\mathrm{A} \beta$ to normal cell cultures, and the $A \beta$ oligomers induced by $\mathrm{Zn}$ have been shown to elicit toxic responses in the hippocampal brain. It should be noted here that the synapse is the site where $\mathrm{A} \beta, \mathrm{Cu}, \mathrm{Zn}$, and $\mathrm{Fe}$ ions are present in sufficiently high quantities to promote interaction. Bush et al. have investigated the reaction between amyloid protein and copper (II) ion, and have pointed out that oligomeric $A \beta$ (1-42) binds with copper(II) ions, and this $\mathrm{A} \beta-\mathrm{Cu}$ complexes generate neurotoxic $\mathrm{H}_{2} \mathrm{O}_{2}$ from $\mathrm{O}_{2}$ (Opaza et al. 2002), but the reaction mechanism of the $\mathrm{H}_{2} \mathrm{O}_{2}$ formation in this process is not known.

\section{Parkinson's Disease and Alpha-synuclein}

Alpha-synuclein ( $\alpha$-syn) is small, natively unfolded protein. It is part of family of similar proteins that include beta-synuclein ( $\beta$-syn) and gamma-synuclein $(\gamma$-syn). While the normal function of these proteins remains uncertain, $\alpha$-syn is a protein that forms aggregate and is known to be associated with certain diseases such as Parkinson's disease (PD) (Wang, Moulla, Wright, \& Brown, 2010; Wright, Wang, \& Brown, 2009). Aggregations of $\alpha$-syn are found within cells and in the brain of patients often in the form inclusions termed Levy Bodies (Bourdenx, Bezard, \& Dehay, 2014; Wang, Moulla, Wright, \& Brown, 2010; Wright, Wang, \& Brown, 2009). The 
mechanism of formation and the possible role of insoluble Levy Bodies in the brain of PD patients remain unclear.

Neuronal loss in PD is highly specific with loss of neurons in the Substantia nigra, but it remains controversial as to whether the cause of death is the result of aggregated $\alpha$-syn within cells, toxicity of extracellular $\alpha$-syn or another mechanism. The survival of neurons in the brain containing aggregated $\alpha$-syn clearly indicates that the presence of aggregated $\alpha$-syn is not sufficient for toxicity and that other factors must be involved. Brown et al. reported that the toxic species is likely to be oligomeric $\alpha$-syn, and that extracellular toxicity of $\alpha$-syn requires the interaction with copper which results in the formation a unique type of oligomeric species (Wang, Moulla, Wright, \& Brown, 2010; Wright, Wang, \& Brown, 2009), but detailed mechanism of the toxicity due to copper(II) ions is not elucidated at present.

\section{Oligomeric Proteins and Metal Ions}

As discussed above, it has been pointed out that the toxicity due to oligomeric proteins is notable, but the origin of the toxicity due to the oligomers remains unsolved at present. In our previous paper, we have reported that A $\beta$ (1-40) interacts with several copper(II) chelates to induce the formation of copper(II) species with short $\mathrm{Cu}-\mathrm{Cu}$ distance ( 3.0-3.5 A), which are called as a binuclear compound (Kishita, Nishino, \& Nishida, 2005), leading to assumption that such binuclear metal compounds where two metal ins are close vicinity, may form facilely in the reaction mixture of oligomers of protein and metal ions, such as copper or iron ion. It should be noted here that these binuclear metal chelates exhibit unique reactivity in the presence of reducing agents and oxygen (Nishida, 2012b), as follows.

\subsection{Nishida Reaction Observed for Binuclear Iron(III) Compounds}

In 1985, Nishida et al. have reported that some binuclear iron(III) compounds, such as $\left[\mathrm{Fe}_{2}(\mathrm{HPTB})(\mathrm{OH})\left(\mathrm{NO}_{3}\right)_{2}\right]^{2+}$ (see Figure 1) can effectively produce hydrogen peroxide in the presence of TMPD $\left(N, N, N^{\prime}, N^{\prime}\right.$-tetramethyl-p-phenylenediamine), one of the famous one-electron donor (Nishida, Takeuchi, Shimo, \& Kida, 1985a). According to the detailed investigation, it has become apparent that formation of hydrogen peroxide proceeds without the change of the oxidation state of iron(III) ion, i.e., reduction to the $\mathrm{Fe}^{2+}$ state does not occur in the reaction course, instead the electron transfer from TMPD to oxygen occurs concertedly through the formation of the intermediate demonstrated in Figure 2 (Nishida 2004, 2011, 2012a). We also found that $\left[\mathrm{Fe}_{2}(\mathrm{HPTB})(\mathrm{OH})\left(\mathrm{NO}_{3}\right)_{2}\right]^{2+}$ complex reacts with linolenic acid (one of the unsaturated fatty-acids) and DMPO (one of the spin-trapping reagents for hydroxyl radical) to give the peroxide adduct of linolenic acid and DMPO-OH, respectively (Nishida \& Yamada, 1990; Nishida, Nasu, \& Akamatsu, 1992). The latter reactions have been also assumed to proceed via the formation of the intermediate similar to that described in Figure 2, and these are called as Nishida Reaction. (Nishida, 2004, 2012a, 2012b)

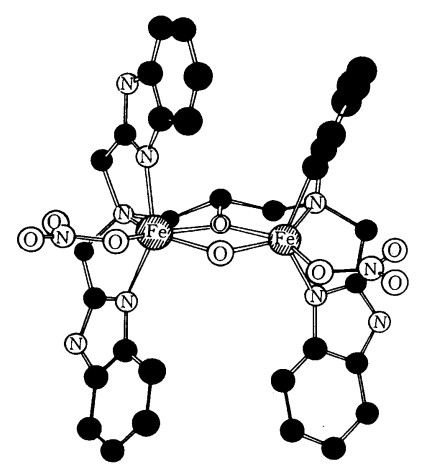

Figure 1. Structure of binuclear of $\left[\mathrm{Fe}_{2}(\mathrm{HPTB})(\mathrm{OH})\left(\mathrm{NO}_{3}\right)_{2}\right]^{2+}$ complex

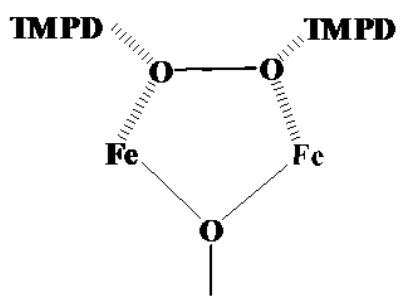

Figure 2. Intermediate complex among binuclear iron(III) complex, oxygen and TMPD where electron transfer from TMPD to oxygen occurs concertedly. 


\subsection{Nishida Reaction Observed for Binuclear Copper(II) Compounds}

The similar reactions as observed for the binuclear iron(III) compounds are also found for the binuclear copper(II) compounds, i.e., some binuclear copper(II) complexes can effectively give hydrogen peroxide in the presence of TMPD, without changing the oxidation state of copper(II) ion (Nishida, Oishi, \& Kida, 1980; Nishida, Oishi, Kuramoto, \& Kida, 1982; Nishida, Shimo, Maehara, \& Kida, 1985b). In addition to this, we also reported that some binuclear copper(II) compounds exhibit high activity for two-electron oxidation of catechols and ascorbic acid by $\mathrm{O}_{2}$, but this reactivity was never observed for any mono-nuclear copper(II) complexes (Oishi, Nishida, \& Kida, 1980). Based on these facts, we have concluded that two-electron oxidation of ascorbic acid or catechols proceeds through the formation of intermediate as illustrated in Figure 3 via concerted manner from ascorbic acid or catechols to oxygen without change of the oxidation state of copper(II) ion (Nishida, 2007; 2011; 2012b), to give hydrogen peroxide. (Abe \& Nishida, 2008)

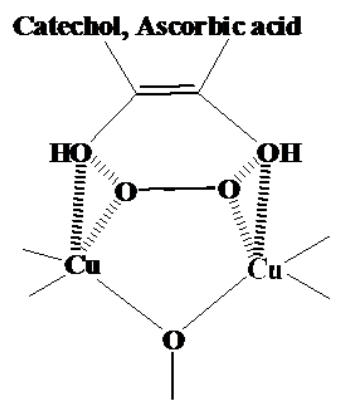

Figure 3. Intermediate complex formation among ascorbate (or catechol), binuclear copper(II) complex and oxygen.

\section{Toxicity Due to Oligomeric A $\beta$ Induced by Copper(II) ion}

The Nishida Reaction is very specific for the binuclear metal chelates with M-M distance 3.0-3.5 A, i.e., the distance between two metal ions is a very important factor (Nishida, Oishi, \& Kida, 1980; Nishida, Oishi, Kuramoto, \& Kida, 1982). Our report that $A \beta(1-40)$ can interact with several copper(II) chelates to induce the formation of copper(II) species with short $\mathrm{Cu}-\mathrm{Cu}$ distance (Kishita, Nishino, \& Nishida, 2005), implying that the interaction with oligomeric $\mathrm{A} \beta$ and copper(II) ions in plasma may facilely give some copper(II) species with short $\mathrm{Cu}-\mathrm{Cu}$ distance (Hureus \& Faller, 2009), which can produce hydrogen peroxide in the presence of reducing agents such as ascorbate and catechols, etc. These seem to be quite consistent with the fact that toxicity of A $\beta$ in neuronal culture is catalytic $\mathrm{H}_{2} \mathrm{O}_{2}$ production, and $\mathrm{A} \beta$ is not toxic in the absence of copper(II) ion, as reported out by Bush et al. (Opaza et al., 2002; Nishida \& Nishino, 1999)

Bush et al. have investigated the reaction between amyloid protein and copper(II) ion, and have pointed out that $\mathrm{A} \beta$ (1-42) forms an oligomeric species that binds with copper(II) ions at a CuZn superoxide dismutase-like binding site, and that $\mathrm{A} \beta$ (1-42), when binding up to 2 equivalent of copper(II) ion, generates $\mathrm{H}_{2} \mathrm{O}_{2}$ catalytically by biological reducing agents as substrates under conditions where the copper(II) ion or reducing agents do not form $\mathrm{H}_{2} \mathrm{O}_{2}$ themselves, and that vitamin C, L-DOPA and dopamine are important substrates for this activity. It should be noted here that all the facts observed by Bush et al. are comprehensively elucidated in terms of the reaction intermediate as illustrated in Figure 3, i.e., Nishida Reaction, because L-DOPA and dopamine are one of the catecholic compounds.

They also observed that cholesterol is an important substrate for the production of $\mathrm{H}_{2} \mathrm{O}_{2}$, and showed that $\mathrm{A} \beta: \mathrm{Cu}^{2+}$ complex oxidizes cholesterol selectively at the $\mathrm{C}-3$ hydroxy group, catalytically producing 4-cholesten-3-one, similar to the activity of cholesterol oxidase (Puglielli et al. 2005). We have done DFT calculations for the cholesterol compound, and found that the electronic property of the HOMO of the cholesterol is very similar to those of the unsaturated fatty acids, as shown in Figure 4. Based on these facts, we have concluded that the oxidation of cholesterol should proceed via the formation of intermediate shown in Figure 4 where oxygen molecule is incorporated through the charge-transfer interaction as proposed for the unsaturated fatty acid (Nishida, 2012d), to give the 6-hydroperoxy derivative of the cholesterol, degrading to the 4-cholesten-3-one. (see Figure 5). 


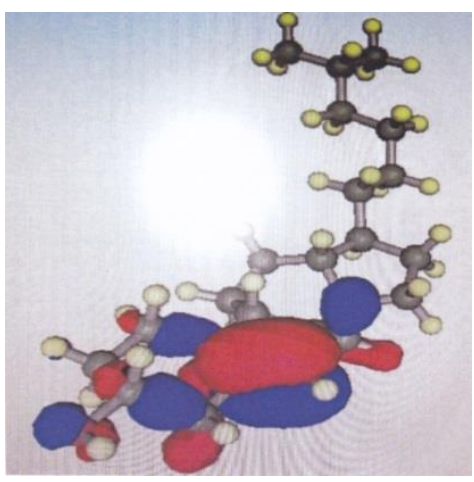

Figure 4. HOMO of cholesterol molecule develops on the carbon atoms of double bond, and also on the adjacent carbon atoms.

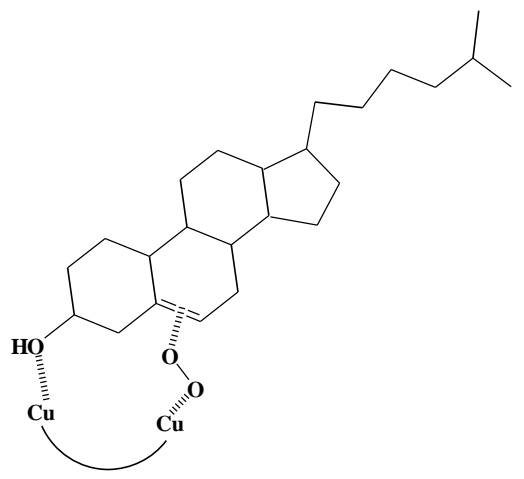

Figure 5. Assumed intermediate among cholesterol, oxygen and copper(II) ion according to the Nishida's scheme for lipoxygenase (Nishida 2012d)

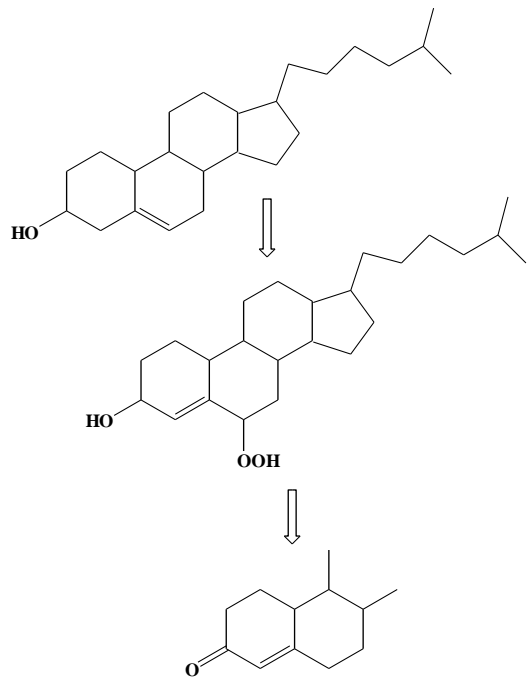

Figure 6. Assumed scheme for formation of 4-cholesten-3-one from cholesterol

In our previous papers, we have reported that in the presence of hydrogen peroxide some copper(II) complexes show high catalytic activities for degradation of several proteins and for cleavage reaction of DNA (Nishida, 2004, 2007, 2011, 2012b). Based on these facts we may conclude that A $\beta$ toxicity induced by the copper(II) ion can be elucidated as follows; in the presence of some reducing agents, hydrogen peroxide forms facilely in the mixture of oligomeric $A \beta$ and copper(II) ions according to the Nishida Reaction, and this hydrogen peroxide gives serious damages to the peripheral organic compounds such as proteins, DNA, or RNA through forming a $\mathrm{Cu}$ (II)-peroxide adduct, which exhibits strong electrophilicity towards several organic compounds similar to singlet oxygen $\left({ }^{1} \Delta_{\mathrm{g}}\right)$ (Nishida, 2004; 2007, 2012b).

\section{Toxicity Due to Oligomeric Alpha-synuclein Induced by Copper(II) ion}

Brown et al. have concluded that only aggregated $\alpha$-syn is neurotoxic and requires the presence of copper but 
not iron ion (Wang, Moulla, Wright, \& Brown, 2010; Wright, Wang, \& Brown, 2009). We would like to propose that the toxic effects on the oligomeric $\alpha$-syn induced by the copper (II) ion should be elucidated by the similar manner as described above for the toxicity of oligomeric $A \beta$ peptides. In addition to above, it should be noted that $\alpha$-syn oligomers bind synthetic phospholipid vesicles much strongly than monomer or fibril (Volles et al. 2001; Ding, Lee, Rochet, \& Lansbury, 2002), suggesting that $\alpha$-syn- $\mathrm{Cu}^{2+}$ complex can effectively produces peroxides the unsaturated fatty acids in the membrane according to Nishida Reaction, which should induce serious oxidative damages to several organs.

The mechanism of formation and the role of the Levy Bodies in the specific loss of neurons in the brain of PD patients remain unsolved. In our previous papers, we have concluded that amyloid plaques formation is induced by zinc(II) ions in order to protect the toxicity due to non-transferrin-bound iron, and amyloid plaques are itself not toxic. (Nishida, 2012b, 2012c) Based on the facts that iron deposition containing several proteins occurs in the presence of a Fe(III) species and hydrogen peroxide (Nishida, 2012c, 2012a, Peng et al., 2010), it is quite likely that Levy Bodies are produced through the interactions among $\alpha$-syn protein, iron(III) ions and hydrogen peroxide which is derived from the Nishida Reaction, and thus Levy Bodies itself are non-toxic, but at the same time of its formation serious damages to cells are induced by the strong electrophilicity of copper(II)-peroxide and/or iron(III)-peroxide adducts (Nishida, 2007, 2012a, 2012b), which should be the main origin for the observed specific loss of neurons in the brain of PD patients. The above discussion seems to be quite consistent with the suggestion that $\alpha$-syn acts in concert with iron and dopamine to induce formation of Levy body pathology and cell death in PD (O-Golts et al. 2000).

\section{Other Neurodegenerative Disorders Which Are Related with Toxicity by Copper(II) ion}

The eukaryotic Superoxide dismutase (SOD) contains copper and zinc ions and catalyzes the dismutation of superoxide ion into hydrogen peroxide and oxygen. (Matsumoto \& Fridovich, 2002) Amyotrophic lateral sclerosis (ALS) is a neurodegenerative disorder characterized by the destruction of large motor neurons in the spinal cord and brain (Matsumoto \& Fridovich, 2002), and familial ALS (fALS) cases are known to be closely associated with dominantly inherited mutations in SOD1which induces the facile dissociation of the SOD dimer to monomers. (Rakhit et al. 2004, Nishida 2007, 2011) Rakhit et al. have reported that dimeric SOD dissociates to monomers for both wild-type and mutant SOD in the presence of copper (II) chloride and ascorbic acid by the use of DLS, but they did not the show the origin of this fact.

We have demonstrated that dissociation of dimeric SOD facilely proceeds in the presence of hydrogen peroxide (see Figure 7) in terms of capillary electrophoresis method (CE) (Chiba, Sutoh, \& Nihsida, 2006). Since the similar CE changes are observed for the solution containing wild-type SOD, copper(II) chloride and ascorbic acid, and also in the presence of ascorbic acid and several binuclear copper(II) chelates such as H(HPTP) or $\mathrm{H}_{5}$ (HPTA) (Abe \& Nishida, 2008), we have concluded that the dissociation of the wild-type SOD observed by Rakhit et al. should be induced by the hydrogen peroxide, which is derived from the copper(II) ions and ascorbic acid as described in Figure 3; i.e., in the system containing wild-type dimeric SOD, copper(II) chloride and ascorbic acid, the copper(II) ions added may form the copper(II) chelate with dimeric SOD protein where two copper(II) ions are in close vicinity, and this will give hydrogen peroxide in the reaction with ascorbic acid.

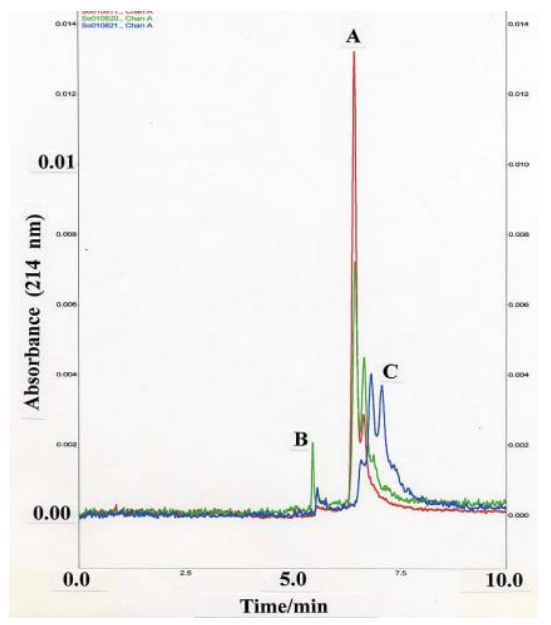

Figure 7. CE profiles of the solutions. A(red): SOD $(1 \mathrm{mg} / 1 \mathrm{~mL})$. $\mathrm{B}(\mathrm{green})$ : Hydrogen peroxide was added to the solution A (measured immediately added; $\left(\left[\mathrm{H}_{2} \mathrm{O}_{2}\right] /\left[\mathrm{Cu}^{2+}\right]=5\right)$. $\mathrm{C}($ blue): Measured at 60 minutes after hydrogen peroxide was added. 


\section{Why Do Iron Ions not Exhibit Toxicity in the Solution of Oligomeric $\alpha$-synuclein?}

Brown et al. have reported that only aggregated $\alpha$-syn is neurotoxic and requires the presence of copper but not iron ion (Wang, Moulla, Wright, \& Brown, 2010; Wright, Wang, \& Brown, 2009). This should be due to that they used the $\mathrm{FeCl}_{3}$ in their experiments. It is quite clear that $\mathrm{Fe}(\mathrm{III})$ ions facilely hydrolyze to form polymeric $\mathrm{Fe}(\mathrm{III})-\mathrm{OH}$ compound in the solution of $\mathrm{pH} \sim 8$, and these polymeric $\mathrm{Fe}(\mathrm{III})-\mathrm{OH}$ compounds cannot interact with the proteins, hydrogen peroxide, and ascrobate. Thus toxicity due to iron (III) ions was not observed in the solution containing oligomeric $\alpha$-syn and $\mathrm{FeCl}_{3}$ in the report by Brown et al., although the severe toxicity due to iron ions and $\alpha$-syn was observed by Golts et al. (Golts, et al. 2000) where they used $\mathrm{FeCl}_{2}$ instead of $\mathrm{FeCl}_{3}$ at $\mathrm{pH} 7.4$.

\section{References}

Abe, K., \& Nishida, Y. (2008). Capillary electrophoresis study on the dimeric SOD enzyme in the presence of ascorbic acid. Z. Naturforsch., 63c, 151-153. http://www.znaturforsch.com/s63c/s63c0151.pdf

Bourdenx, M., Bezard, E., \& Dehay, B. (2014). Lysosomes and $\alpha$-synuclein form a dangerous duet leading to neuronal cell death. Frontiers in Neuroantomy, 8, 1-7. Http://dx.doi.org/10.3389/fnana. 2-14.00083.

Chiba, Y., Sutoh, Y., \& Nishida, Y. (2006). Detection of structural change of superoxide dismutase in solution. $Z$. Naturforsch. 61c, 273-277. http://www.znaturforsch.com/ac/v61c/s61c0273.pdf

Ding, T. T., Lee, S. J., Rochet, J. C., \& Lansbury, P. T. (2002). Annular alpha-synuclein protofibrils are produced when spherical protofibrils are incubated insoution or bound to brain-derived membranes. Biochemistry, 41, 10209-10217.

Gaeta, A., \& Hider, R. C. (2005). The crucial role of metal ions in neurodegeneration: the basis for a promising therapeutic strategy. Brit. J. Pharm., 146, 1041-1059. http://dx.doi.org/10.1038/sj.bip.0706416

Hureau, C., \& Faller, P. (2009). Abeta-mediated ROS production by $\mathrm{Cu}$ ions: structural insights, mechanism and relevance to Alzheimer's disease. Biochimie, 91, 1212-1217

Kenche, V. B., \& Barnham, K. J. (2011). Alzheimer's disease and metals; therapeutic opportunities. Brit. J. Pharm., 161, 211-219. http://dx.doi.org/10.1111/j.1476-5381.2011.012221.x

Kishita, A., Nishino, S., \& Nishida, Y. (2005). Interaction between $\mathrm{Cu}(\mathrm{II})$ compounds and amyloid $\beta$-peptide (1-40) in solution. Synth. Reac. Inorg. Metal-org. Nano-metal. Chem., 35, 379-383. http://dx.doi.org/10.1081/SIM-200059209

Matsumoto, A., \& Fridovich, I. (2002). Amyotrophic lateral sclerosis: A propose mechanism. Proc. Natl. Acad. Sci. USA, 99, 9010-9014.

Nishida, Y., \& Nishino, S. (1999). Contribution of a metal-peroxide adduct to neurodegeneration is due its oxidative protease activity. Z. Naturforsch., 54C, 1107-1112.

Nishida, Y. (2004). Oxidative stress and neurodegeneration. Med. Hypothesis Res., 1, 227-245.

Nishida, Y. (2007). Structural change of dimeric SOD enzyme and amyotrophic lateral sclerosis(ALS), TCIMail, 135, 2-11. http://www.tciamerica.com/tcimail/backnumber/article/135drE.PDF

Nishida, Y. (2011). The chemical process of oxidative stress by copper(II) and iron(III) ions in several neurodegenerative disorders. Monatsh. Chem. 142, 375-384. http://dx.doi.org/10.1007/s00706- 0100444-8

Nishida, Y. (2012a). The chemical mechanism of oxidative stress due to non-transferrin-bound iron (NTBI). Adv. Biosci. Biotech., 3, 1076-1086. http://dx.doi.org/10.4236/abb.2012-217131

Nishida, Y. (2012b). "Oxygen activation, oxidative stress and human health", LAP Publishing, Saarbrucken, Germany.

Nishida, Y. (2012c). Role of zinc(II) ion for the formation of iron deposition in human body and its significance. Int. J. Chem., 4, No. 6, 1-6. http://dx.doi.org/10.5539/ijc.v4n6p1

Nishida, Y. (2012d). Oxygen activation in lipoxygenase model reaction studied with density functional theory. Int. J. Chem. 4, No.4,1-6. http://dx.doi.org/10.5539/ijc.v4n1p1

Nishida, Y., Nasu, M., \& Akamatsu, T. (1992). Reaction between binuclear iron(III) compounds and DMPO. J. Chem. Soc. Chem. Commun., 93-94.

Nishida, Y., Oishi, N., \& Kida, S. (1980). Reaction between several binuclear copper(II) complexes and one-electron donor such as TMPD. Inorg. Chim. Acta, 46, L69-70. 
Nishida, Y., Oishi, N., Kuramoto, H., \& Kida, S. (1982). Importance of structural factor in the catalytic activity of copper(II) complexes for the oxidation of TMPD by oxygen. Inorg. Chim. Acta, 57, 253-256.

Nishida, Y., Takeuchi, M., Shimo, H., \& Kida, S. (1985a). Synthesis and reactivities of binuclear iron(III) complexes with ligands composed of two tridentate chelating groups. Inorg. Chim. Acta, 96, 115-119.

Nishida, Y., Shimo, H., Maehara, H., \& Kida, S. (1985b). Crystal structure and magnetic properties of binuclear five-coordinate copper(II) complexes with a phenolate bridge and their catalytic function in multielectron redox reaction. J. Chem. Soc. Dalton Trans., 1945-1951.

Nishida, Y., \& Yamada, K. (1990). Lipoxygenase-like function of some binuclear iron(III) complexes. J. Chem. Soc. Dalton Trans., 3639-3641.

O-Golts, N., Petrucelli, L., Hardy, J., Lee, J. M., Farer, M., \& Wolozin, B. (2000). The A53T $\alpha$-synuclein mutation increases iron-dependent aggregation and toxicity. J. Neuroscience., 20, 6048-6054.

Oishi, N., Nishida, Y., \& Kida, S. (1980). Reaction between various copper(II) complexes and ascorbic acid or 3,5-di-tert-butylcatechol. Bull Chem. Soc. Jpn., 53, 2847-2850.

Opaza, C., Huang, X., Chermy, R. A., Moir, R. D., Rohe, A. E., White, A. R., Cappi, R., Masters, C. L., Tanzi, R. E., Inesstrosa, N. C., \& Bush, A. I. (2002). Metalloenzyme-like activity of Alzheimer's disease $\beta$-amyloid: $\mathrm{Cu}$-dependent catalytic conversion of dopamine, cholesterol, and biological reducing agents to neurotoxic $\mathrm{H}_{2} \mathrm{O}_{2}$. J. Biol. Chem., 277, 40302-40308. http://dx.doi.org/10.1074/ jbc.M206428200.

Peng, Y., Wang, C., Xu, H., Liu, Y. N., \& Zhou, F. (2010). Binding of $\alpha$-synuclein with Fe(III) and Fe(II) and biological implications of the resultant complexes. J. Inorg. Biochem., 104, 365-370. http://dx.doi.org/10.1016/j.jinorgbio.2009.11.005.

Puglielli, L., Friedlich, A. L., Setchell, K D. R, Nagano, S., Opazo, C., Cherny, R. A., Barnham, K. J., Wade, J. D, Melov, S., Kovas, N. C., \& Bush, A. I. (2005). Alzheimer disease $\beta$-amyloid activity mimics cholesterol oxidase. J. Clinical Inves., 115, 2556-2563. http://dx.doi.org/10.1172/JCI23610.

Rakhit, R, Crow, J. P, Lepock, J. Z., Kondejewski, L. H., Cashman, N. R., \& Chakrabarty, A. (2004). Monomeric $\mathrm{Cu}, \mathrm{Zn}$-superoxide dismutase is a common misfolding intermediate in the oxidation models of sporadic and familial amyotrophic lateral sclerosis. J. Biol. Chem., 279, 15499-15504.

Roberts, B. R., Ryan, T. M., Bush, A. I., Masters, C. L., \& Duce, J. A. (2012). The role of metallobiology and amyloid- $\beta$ peptide in Alzheimer's disease. $J$. Neurochemistry, 120, 149-166. http://dx.doi.org/10.1111/j.1471-4159.2011.07500.x.

Volles, M. J., Lee, S. J., Rochet, J. C., Shtilerman, M. D., Ding, T. T., Kessler, J. C., \& Lansbury, P. T. (2001). Vesicle permeabilization by protofibrillar alpha-synuclein: implications for the pathogenesis and treatment of Parkinson's disease. Biochemistry, 40, 7812-7819.

Wright, J. A., Wang, X., \& Brown, D. R. (2009). Unique copper-induced oligomers mediate alpha-synuclein toxicity. FASEB J. 23, 2384-2389.

Wang, X., Moulla, D., Wright, J. A., \& Brown, D. R. (2010). Copper binding regulates intracellular alpha-synuclein localization, aggregation and toxicity. J. Neurochemistry, 113, 704-714.

\section{Copyrights}

Copyright for this article is retained by the author(s), with first publication rights granted to the journal.

This is an open-access article distributed under the terms and conditions of the Creative Commons Attribution license (http://creativecommons.org/licenses/by/3.0/). 